\title{
Climate Change Impact on Monthly Precipitation Wet and Dry Spells in Arid Regions: Case Study over Wadi Al-Lith Basin
}

\author{
Mansour Almazroui, ${ }^{1}$ Khaled S. Balkhair, ${ }^{2,3}$ M. Nazrul Islam, ${ }^{1}$ and Zekai Şen ${ }^{1}$ \\ ${ }^{1}$ Center of Excellence for Climate Change Research, Department of Meteorology, King Abdulaziz University, Jeddah, Saudi Arabia \\ ${ }^{2}$ Department of Hydrology and Water Resources Management, King Abdulaziz University, Jeddah, Saudi Arabia \\ ${ }^{3}$ Center of Excellence in Desalination Technology, King Abdulaziz University, Jeddah, Saudi Arabia \\ Correspondence should be addressed to Mansour Almazroui; mansour@kau.edu.sa
}

Received 19 April 2017; Revised 17 June 2017; Accepted 23 August 2017; Published 4 October 2017

Academic Editor: Roberto Fraile

Copyright (C) 2017 Mansour Almazroui et al. This is an open access article distributed under the Creative Commons Attribution License, which permits unrestricted use, distribution, and reproduction in any medium, provided the original work is properly cited.

\begin{abstract}
Durations of monthly precipitation wet and dry spells are calculated using historical records and regional climate model (RCM) simulations for the Wadi Al-Lith basin in western Saudi Arabia. The characteristics of durations of wet and dry spells are based on the 50\% risk level corresponding to the monthly records for average regional precipitation. The duration of wet spells in the model data is compared with observations for the base period 1971-2000. The impact of climate change on the durations of wet and dry spells is obtained using three global climate models projections with RCP4.5 and RCP8.5 scenarios downscaled by RCM. The probability distribution functions (PDFs) of the climate model scenarios and the precipitation records for the base period prove that climate change has a clear impact on the durations of wet and dry spells over the study area. There is an increase in wet spells frequency in the far future (2070-2099) compared to the near future (2020-2049). The increase in wet spells can be partly explained by the increase in extreme rainfall events and by the decrease in dry spells expected to occur over the study area towards the end of 21st century.
\end{abstract}

\section{Introduction}

The precipitation statistics for wet and dry spells are important for the planning and management of water resources. They are particularly valuable for arid and semiarid regions due to their high temporal and spatial variability. In general, the term "wet spell" refers to the periods of intense precipitation, which creates water surpluses and may cause occasional floods or flash floods in arid regions. On the other hand, "dry spell" refers to periods of precipitation deficits resulting in occasional water shortages, droughts, and arid conditions. The fundamental features of dry spells, and especially droughts, are presented in detail by Şen [1]. In general, wet and dry spells are identified according to duration, intensity, severity, and spatiotemporal spread from daily or more often monthly data. Monthly precipitation records provide basic data allowing the detection of meteorological, hydrological, or agricultural drought, which is defined as the inability to provide a society with its necessary water requirements [1-4].
Furthermore, wet and dry spells affect water quality in a drainage basin, which in turn may have health implications for a society [5]. For better water resource management, surplus water from wet spells should be stored either in surface reservoirs or in underground water storage facilities to supplement water supply during subsequent drought periods. Many researchers have explored the probability and statistical features of successive monthly wet and dry spells especially for drought analysis by using different scientific methodologies [3, 6-12]. Most of the literature is concerned with the probabilistic, statistical, and stochastic modeling of which the most widely used stochastic models are autoregressive integrated moving average (ARIMA) models [13]. Several authors have pointed out that a first-order Markov chain model may provide improved results [14-16]. However, for water resource management, apart from these procedures, identification of wet and dry spell characteristics by probabilistic and statistical methodologies is very important. For this purpose, it is necessary to consider a given precipitation 
TABLE 1: Name and coordinates of stations in and around Wadi Al-Lith.

\begin{tabular}{lccccc}
\hline SL number & Station name & Longitudes $\mathrm{E}^{\circ}$ & Latitudes $^{\circ}$ & Annual rainfall $(\mathrm{mm})$ & Elevation $(\mathrm{m})^{\circ}$ \\
\hline$(1)$ & TA233 & 40.650 & 21.133 & 219.83 & 2640 \\
$(2)$ & TA109 & 40.367 & 21.067 & 320.35 & 2632 \\
$(3)$ & J107 & 40.450 & 20.317 & 63.117 & 88 \\
$(4)$ & J108 & 40.283 & 20.150 & 44.89 & 20 \\
\hline
\end{tabular}

record with respect to a threshold level so as to identify characteristic behaviors of the wet and dry spells within the record. Duration is one of the characteristics of a precipitation spell while others are intensity, magnitude, and frequency. In general, the duration of wet or dry spells is defined in terms of water supply and demand levels. If water supply is greater (less) than demand, then this duration is considered to be a wet (dry) spell. Prolonged durations of water deficit are defined as drought [17]. Usually the daily precipitation is used to define wet and dry spells. However this analysis considers monthly precipitation rather than daily data because, as for many arid regions, most daily rainfall records are zero in Saudi Arabia.

One of the characteristics of many precipitation regimes throughout the world is that wet duration occurs in a variety of lengths. Monthly precipitation records may be analyzed simply using a given risk level, which also helps to identify the critical magnitudes of monthly wet and dry spell features with respect to a truncation level. On the other hand, the geographical distribution parameters of wet and dry spells for the target area are helpful in the case of new water resource development and planning projects especially related to agricultural activities and environmental engineering $[18,19]$. The impact of climate change on many regions is expected to adversely change the characteristics and frequency (probability) of wet and dry spells [20, 21]. Hydrometeorological variables of wet and dry spells as recorded by monthly precipitation are affected by climate change and this impact may extend over vast areas. Similar effects have been recorded in many regions characterized by increasing drought frequency. Bates et al. [22] highlighted several climate models revealing that deficit anomalies are the main triggers of drought events leading to multiple impacts on human activities. Climate model projections have indicated that summer season precipitation declines by $50 \%$, while persistent temperature increases result in an increase in drought severity of over $40 \%$ in the Mediterranean regions [23, 24].

In order to compensate for losses caused by prolonged dry durations, it is necessary to observe and evaluate dry periods (drought) and subsequent wet phenomena using reliable scientific methods [25]. Almedeij [26] suggested that a projection of dry durations can be achieved by implementation of climate model scenarios. Mishra et al. [27] and Cancelliere and Salas [28] investigated probabilistic characteristics of wet and dry spells to emphasize the important aspects in water resource management. Tsakiris et al. [29] proposed the Reconnaissance Drought Index (RDI) based on the ratio of cumulative precipitation to potential evapotranspiration. Although many studies of climate change scenarios are available, the analysis of duration of wet and dry spells has not been adequately covered for arid regions within the context of climate change impacts. Currently, there is no study on the duration of wet and dry spell over Saudi Arabia using climate model projection data. An understanding of duration of wet and dry spell is important for researchers because it is crucial for water resource management, particularly in arid regions. Therefore, this paper presents the features of duration of wet and dry spell for Wadi Al-Lith, a hydrological basin that drains to the Red Sea, using monthly rainfall records and climate model projection data.

\section{Study Area and Data}

Wadi Al-Lith, located in the western province of Saudi Arabia, is selected as the study area. In this Wadi region $\left(40^{\circ} 10^{\prime}\right.$ and $40^{\circ} 50^{\prime}$ longitude and $20^{\circ}$ and $21^{\circ} 15^{\prime}$ latitude), the altitude varies from zero at the Red Sea coast to more than $2,000 \mathrm{~m}$ above mean sea level on the mountainous side in the east (Figure 1). The catchment area of the Wadi is around $3262 \mathrm{~km}^{2}$. In this study, four meteorology stations (J107, J108, TA109, and TA233) with precipitation records of at least 30year period are considered for the Wadi Al-Lith basin. The names of the meteorological stations with their coordinates are given in Table 1.

The model data is generated using the regional climate model (RCM), namely, RegCM4 driven by three global climate models (GCMs) data as input which are HadGEM2, GFDL, and ECHAM6. RegCM4 is the fourth generation of RegCM developed by the International Centre for Theoretical Physics, Trieste, Italy [30], while the HadGEM2 is the UK Met Office Hadley Centre Global Environment Model version 2 (resolution: $1.88^{\circ} \times 1.25^{\circ}$ ), the GFDL is the USA Geophysical Fluid Dynamics Laboratory model (resolution: $2.50^{\circ} \times 2.00^{\circ}$ ), and the ECHAM6 is the German Atmospheric Global Climate Model of Max Planck Institute for Meteorology (resolution: $1.80^{\circ} \times 1.80^{\circ}$ ). The representative concentration pathways, RCP 4.5 and RCP8.5, are the climate scenarios considered for the projection period, and the RegCM4 domain horizontal resolution is $25 \mathrm{~km} \times 25 \mathrm{~km}$. Model run was completed in 176 lon $\times 98$ lat grids with 18 vertical levels using Grell convection scheme with FritchChappell closure and CLM land surface scheme. The details of RegCM4 runs with other horizontal resolutions and larger domains can be seen in Almazroui [31] and Almazroui et al. $[32,33$. The climate model RegCM4 runs are performed for the entirety of the Arabian Peninsula with RCP4.5 and RCP8.5 scenarios [4]. For the quick view of the performance of RegCM4 in simulation of climatic parameters over Saudi Arabia, the simulated precipitation for the box $41-48^{\circ} \mathrm{E}$ and $20-2^{\circ} \mathrm{N}$ is compared with ERA-Interim $\left(0.75^{\circ} \times 0.75^{\circ}\right.$; 


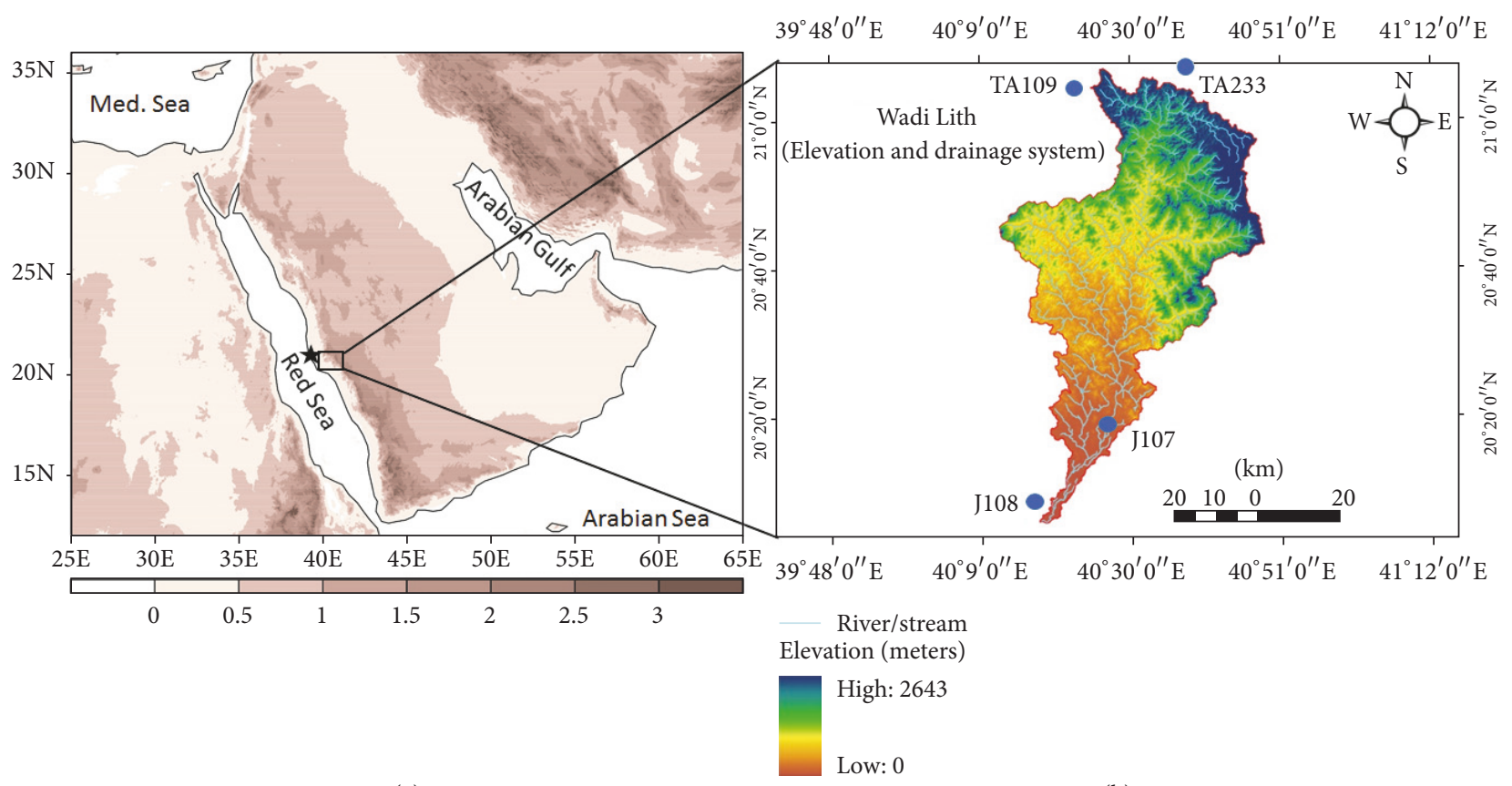

(a)

(b)

Figure 1: Regional map (a) showing Wadi Al-Lith ((b), elevation in meters) in the western province of Saudi Arabia ((a), elevation in km). The map also shows the effective domain of the climate model run to generate climatic variables including precipitation for the present and future climate. The star (a) indicates the location of Jeddah city in the western province of Saudi Arabia while the blue solid circles (b) indicate the locations of the four meteorological stations in and around Wadi Al-Lith.

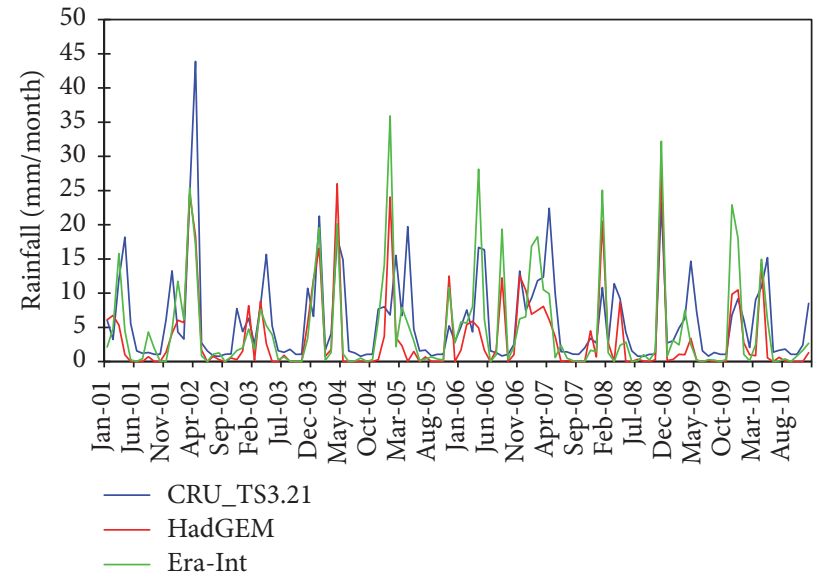

FIGURE 2: The model simulated monthly precipitation with RegCM4 driven with HadGEM and ERA-Int along with observations (CRU) for the period 2001-2010. Precipitation extracted over Saudi Arabia for the box $41-48^{\circ} \mathrm{E}$ and $20-2^{\circ} \mathrm{N}$.

http://apps.ecmwf.int/datasets/data/interim-full-daily/levtype= sfc/) driven data and Climatic Research Unit (CRU) rainfall as an example (Figure 2). The mean precipitation for the period 2001-2010 is $6.03,3.50$, and $4.88 \mathrm{~mm}$ for CRU, HadGEM2, and ERA-Int, respectively. These values account for precipitation bias of -41.90 and $18.98 \%$ for HadGEM 2 and ERA-Int, respectively. The correlation between the HadGEM (ERA-Int) and CRU data is 0.60 (0.58). Also, the pattern of RegCM4 precipitation driven with HadGEM2 is more or less comparable with observations CRU and ERA-Int driven data.

For the purposes of this application, following Almazroui et al. [4], monthly rather than daily precipitation data is considered because, as for many arid regions, most daily records are zero in Saudi Arabia, as mentioned earlier. In general, daily data do not provide relevant background information for most inferential procedures. Daily precipitation forecasts are only one type of weather data that are needed for water supply management purposes. In some situations, water supply managers require daily precipitation information, while in other instances they need to know how much precipitation will occur over a more extended period of time, such as on a weekly or monthly scale.

The following are the types of monthly data used in this study:

(1) For all four stations monthly precipitation records are available for the base period 1971-2000.

(2) The climate model monthly precipitation amount for the control period is also for the same base period.

(3) Projection of monthly precipitation by the model with RCP4.5 and RCP8.5 scenarios is extracted for the period 2020-2099 at the four stations.

(4) Projection of monthly precipitation by the model is considered for two 30-year periods: the near future (2020-2049) and the far future (2070-2099).

Before processing the precipitation data, it is necessary to assess the reliability and quality of the observations available 


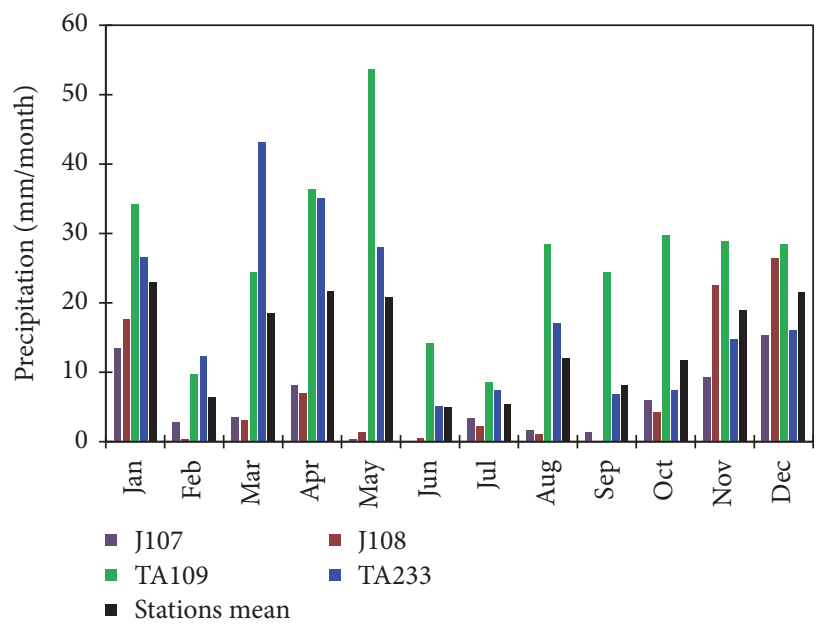

(a) Observation

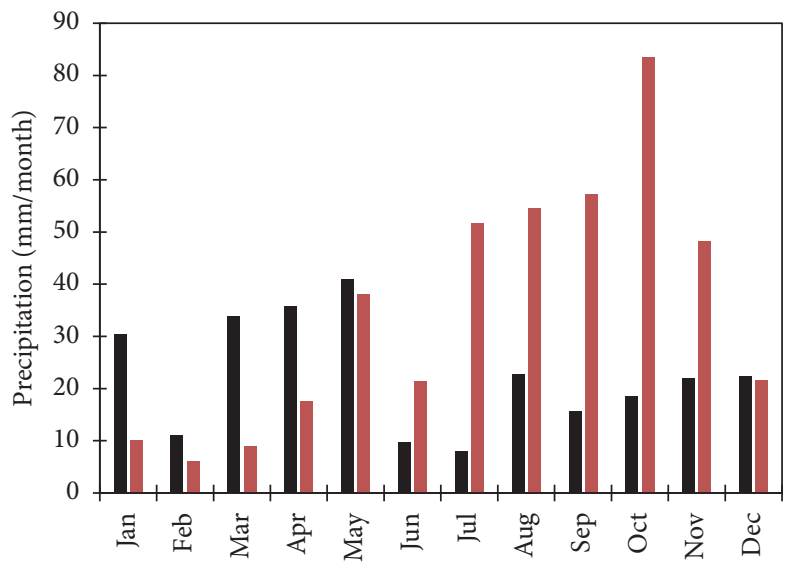

- TA109\&TA223 observed, 1971-2000

- TA109\&TA223 model, 1971-2000

(c) TA109\&TA223

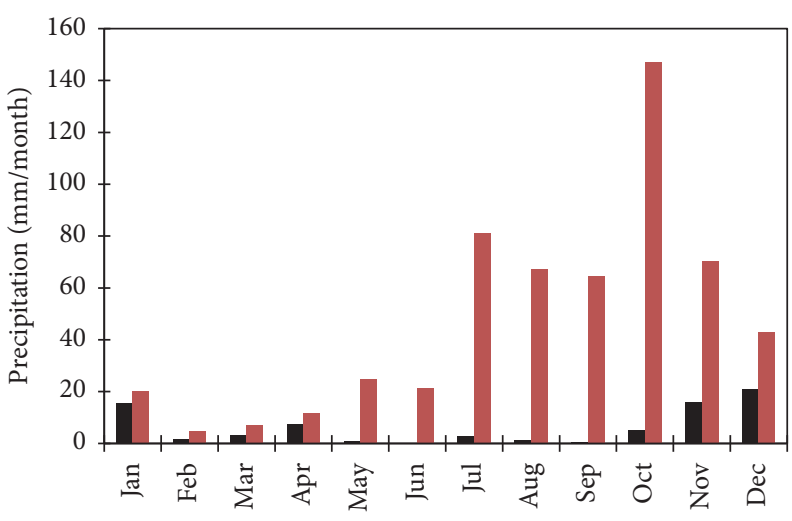

- J107\&J108 observed, 1971-2000

- J107\&J108 model, 1971-2000

(b) J107\&J108

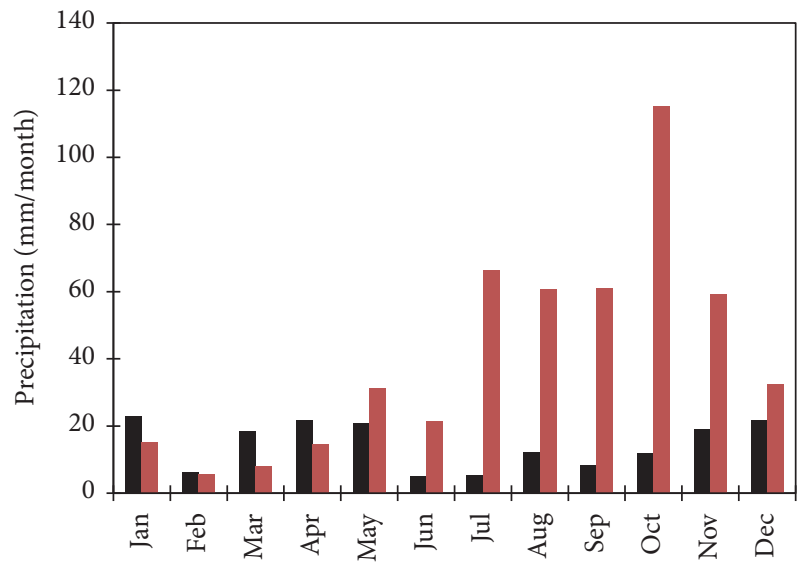

- All stations mean observed, 1971-2000

- All stations mean model, 1971-01

(d) All stations mean

Figure 3: The annual cycle of (a) observed precipitation at four stations and their average (ensemble) over the period 1971-2000. The annual cycle of model precipitation ensemble with the same observations for (b) J107 and J108, (c) TA109 and TA223, and (d) all 4 stations mean.

and then to correct for unreliable data. If there are missing data, they can be filled in from observations by considering at least three stations close to the target station and evenly spaced around it as possible using the normal-ratio method. The precipitation amount at the index station is weighted by the ratio of normal annual precipitation where applicable [34]. Naturally, precipitation varies largely over space and time $[35,36]$ which can be seen in Figure 3(a) from the four station locations in and around Wadi Al-Lith. For the study area, the two downstream stations (J107 and J108) average precipitation simulated by model is largely overestimated compared to the observations (Figure 3(b)). In case of two upstream stations (TA109 and TA223) average precipitation, the model is underestimated from December to May and overestimated from June to November (Figure 3(c)). The four stations' average precipitation simulated by model is largely overestimated compared to the observations (Figure 3(d)). Actually, this is the limitation of climate model in simulation of precipitation. This is one of the reasons to use monthly precipitation instead of daily data. The spatial distribution of rainfall climatology for the study area can be seen in literature [4]. For simplicity of analysis, the arithmetic average from the two downstream stations, two upstream stations, and four stations is taken for further study.

\section{Wet and Dry Durations and Risk Calculation Methodology}

For the study of consecutive rainy, wet (W) and nonrainy, dry (D) days, not only is the duration of the wet or dry spells calculated but also their number, intensity, maximum duration, and, most significantly, the risk assessments are calculated. At the beginning and end of any spell there are two transition states, either in the form wet-dry or dry-wet successions. Readers should keep in mind that, for the first duration to be wet or dry, it will depend directly on whether the first data value is bigger than or equal to the truncation (risk) level. The duration of the consecutive wet and dry 


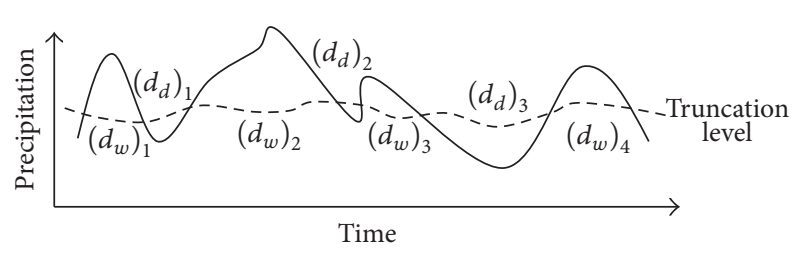

FIGURE 4: Schematic diagram of durations of wet and dry spells at a given truncation level.

spells, in nature, has a random character. For instance, a wet (dry) month is followed by another wet or dry month and as a result clusters of adjacent wet (dry) months lead to wet (dry) spells of longer duration. Thus, the duration of spells depend on the precipitation amount, time of occurrence, and the risk (truncation) level. Figure 4 shows schematically wet and dry duration sequences.

It is not necessary that the truncation level be a constant value as in this paper the truncation levels are adopted as the areal monthly averages corresponding to almost $50 \%$ risk level in each month. It is possible to adopt another risk level, but the procedure presented does not change. In this manner, the nonstationary value in the monthly precipitation series is taken into consideration.

If duration of wet (dry) spells is shown rotationally as $d_{w}\left(d_{d}\right)$, one can see from Figure 4 that

$$
\sum_{i=1}^{n_{w}}\left(d_{w}\right)_{i}+\sum_{j=1}^{n_{d}}\left(d_{d}\right)_{j}=n
$$

where $n_{w}$ and $n_{d}$ are the numbers of wet and dry spells; $n$ is the number of data. On the other hand, the following expression is valid between the numbers of wet and dry spells.

$$
n_{w}=n_{d} \pm 1
$$

Equation (2) shows that the difference between the numbers of wet and dry spells is equal to one. In this study, the threshold value is assumed to be the ensemble arithmetic average of each monthly time series. This corresponds to almost 50\% risk level for each month with different threshold levels. Hence, the periodicity in the monthly precipitation occurrence is taken into consideration.

In developing the risk curves, statistical frequency analysis is employed, whereby monthly precipitation is described by one of the theoretical probability distribution functions (PDFs) including generalized extreme value Gamma, lognormal, generalized extreme value (GEV, Pearson) and extreme value (EV, Gumbel), and distributions. The use of these PDFs depends on the monthly precipitation amounts or the duration of wet (dry) spell in the form of relative frequency distributions (histograms). However, in this paper, the cumulative distribution function (CDF) is preferred for risk descriptions. The general mathematical expression, $f(x)$, of the GEV PDF for the precipitation amount, $x$, is given as

$$
f(x)=\frac{1}{\alpha}\left[1-k\left(\frac{x-u}{\alpha}\right)\right]^{1 / k-1} e^{-[1-k((x-u) / \alpha)]^{1 / k}}
$$

where $\alpha, u$, and $k$ are the model parameters. Extreme value type I Gumbel PDF has the following form [37]:

$$
f(x)=\frac{1}{\alpha} \exp \left[\left(-\frac{x-u}{\alpha}\right)-\exp \left(-\frac{x-u}{\alpha}\right)\right] .
$$

On the other hand, the earliest application of the Gaussian (normal) PDF to hydrologic variables has been presented in a paper on the use of normal probability for analysis of the hydrologic data. This PDF has a bell shape and its general expression can be found in standard textbooks on statistics as

$$
f(x)=\frac{1}{\sigma \sqrt{2 \pi}} e^{\left(1 / 2 \sigma^{2}\right)(x-\mu)^{2}},
$$

where $\mu$ and $\sigma$ are the arithmetic mean and standard deviation values of the intensity values, respectively. It is very important to note that the normal (Gaussian) and exponential PDFs cannot represent annual daily maximum rainfall or flood data.

In order to obtain a skewed PDF, two-parameter lognormal PDF has the following mathematical formulation:

$$
f(x)=\frac{1}{x \sigma_{x} \sqrt{2 \pi}} \exp \left[-\frac{\left(\log x-\mu_{x}\right)^{2}}{2 \sigma_{x}^{2}}\right] .
$$

The three-parameter log-normal distribution is similar except that $x$ is shifted by an amount, $m$, which represents a lower boundary [38]:

$$
f(x)=\frac{1}{(x-m) \sigma_{x} \sqrt{2 \pi}} \exp \left\{-\frac{\left[\operatorname{Ln}(x-m)-\mu_{x}\right]^{2}}{2 \sigma_{x}^{2}}\right\} .
$$

Herein, $\mu_{x}$ and $\sigma_{x}$ are the mean and standard deviations of the intensity value logarithms. A flexible PDF, which also includes the exponential PDF (when $\beta=1$ ), is a twoparameter Gamma PDF, which can be expressed mathematically as

$$
f(x)=\frac{1}{\alpha^{\beta} \Gamma(\beta)} x^{\beta-1} e^{-(x / \alpha)} .
$$

Pearson [39] suggests the PDFs Pearson III and its logarithmic version, Log-Pearson III, be expressed as

$$
\begin{aligned}
& f(x)=\frac{1}{\alpha \Gamma(\beta)}\left(\frac{x-\gamma}{\alpha}\right)^{\beta-1} e^{-((x-\gamma) / \alpha)}, \\
& f(x)=\frac{1}{\alpha x \Gamma(\beta)}\left[\frac{\operatorname{Ln}(x)-\gamma}{\alpha}\right]^{\beta-1} e^{-\{(\operatorname{In}(x)-\gamma) / \alpha\}},
\end{aligned}
$$

respectively.

The recurrence interval, $R$, is inversely related to the exceedance probability, $p$, which is also referred to as the risk level:

$$
R=\frac{1}{p}
$$




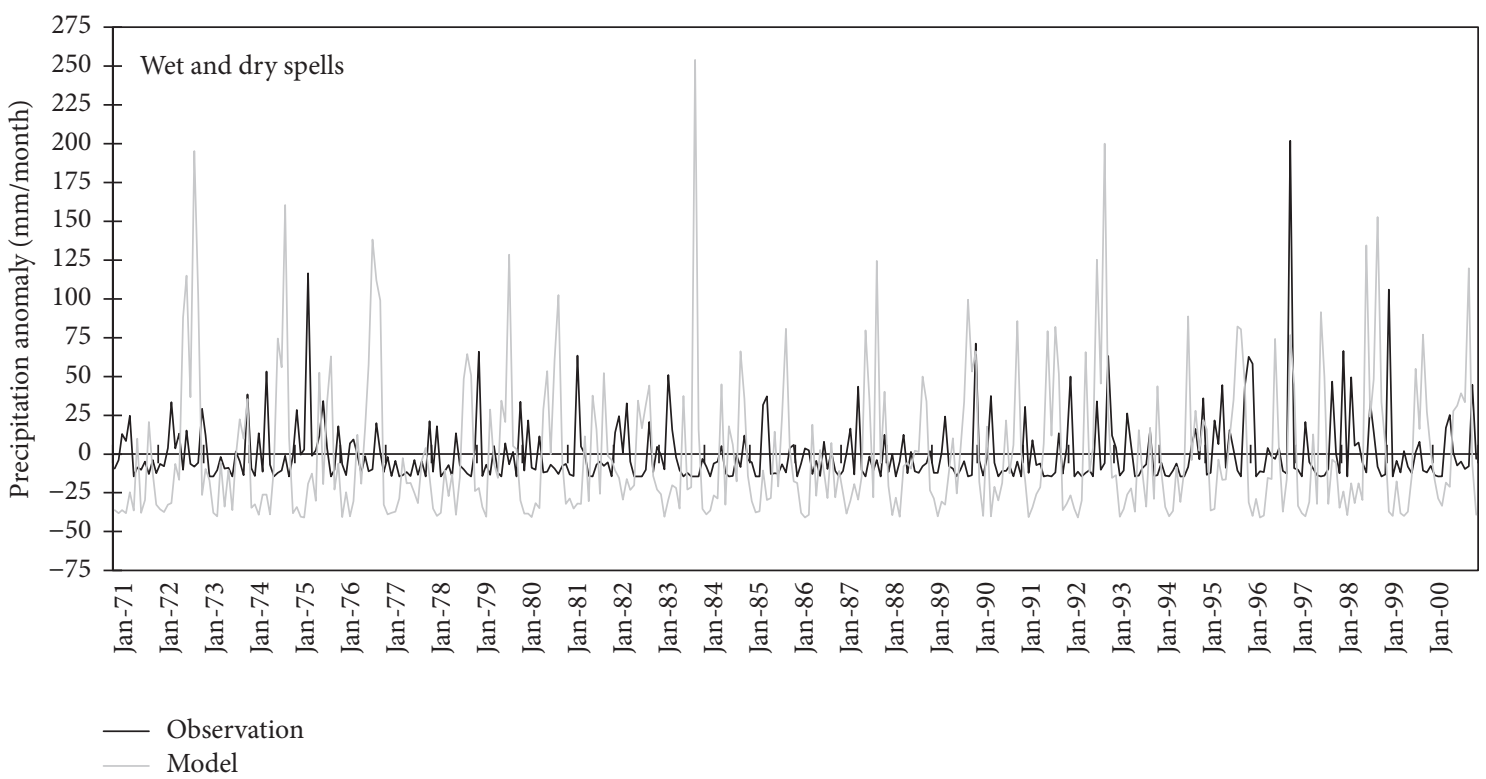

FIGURE 5: Monthly precipitation anomalies obtained from observations and RegCM4 driven with HadGEM2 model data for the period 1971-2000. Zero is the average value over the period 1971-2000 which is equivalent to $14.44 \mathrm{~mm}$ and $40.91 \mathrm{~mm}$ for observations and model, respectively.

The intensity, $i$, as the basis of CDF curves is represented by a suitable PDF, $f(i)$, and hence (11) takes the following form:

$$
R=\frac{1}{\int_{i_{d}}^{+\infty} f(i) d i},
$$

where $i_{d}$ is design value (threshold level) corresponding to a given risk level or return period.

\section{Results and Discussion}

The steps followed in the application of the methodology in this paper are given as follows:

(1) The first step is to determine whether there is a climate change impact on the monthly precipitation amounts. For this purpose, the climate model data is used to identify the wet and dry spells knowing that the climate model data is not free of uncertainties. The precipitation anomalies are used for the base record and RegCM4 driven with HadGEM2 model data as an example (Figure 5). The average precipitation for the period $1971-2000$ is $14.44 \mathrm{~mm}$ and $40.91 \mathrm{~mm}$ for observations and HadGEM2 model, respectively. The RegCM4 when forced with GCM is not designed to be capable of being in phase with observations. Therefore, the simulated precipitation surplus (wet) and deficit (dry) datasets do not match exactly the observations; sometimes they are in phase and sometimes they are out of phase with differences in magnitude. These results are expected given the current status of the climate models; however, the thing worth noting is that the model data can be used for the projection period, an important point for climate change impact studies in understanding changes in wet and dry spells in the future relative to the model base period.

(2) The monthly precipitation wet spells for each year over a 30-year base period provide a time series. If the number of wet spells of monthly duration in one year is $n_{w}$ then the dry spell number, $n_{d}$, is equal to $12-n_{w}$. Figure 6 shows an example of the wet spell time series for observations and RegCM4 driven with HadGEM2 model monthly precipitation amounts for the base period 1971-2000. These graphs represent data averages from the two downstream stations (J107 and J108), two upstream stations (TA109 and TA223), and four stations (J107, J108, TA109, and TA233). For the 30-year period, the model (observation) identified 114 (60) and 133 (120) wet spells for downstream and upstream stations average, respectively (Figures 6(a) and 6(b)). For all stations average, the model identified 117 wet spells compared to 111 for the observations (Figure 6(c)). Hence, it is obvious that, on average, observations and model results show almost the same number of wet spells within $\pm 5 \%$ relative error for all stations average. The overestimation of wet spells by the model data is large (90\%) for the downstream stations average and relatively small for the upstream stations average (11\%). This indicates that although the wet and dry spells in the model data are not entirely in phase with observed data (see Figure 6), the number of wet spells for the same data is similar. Hence, the uncertainty in wet spell detected by the model is about $5 \%$ for all stations average. This information is invaluable in understanding changes in the duration of wet or dry spells during the projected period relative to the base period. 


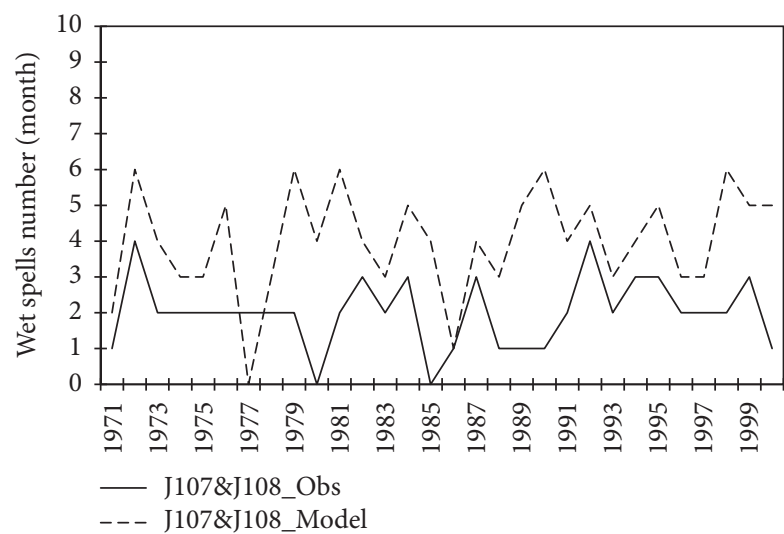

(a) $\mathrm{J} 107 \& \mathrm{~J} 108$

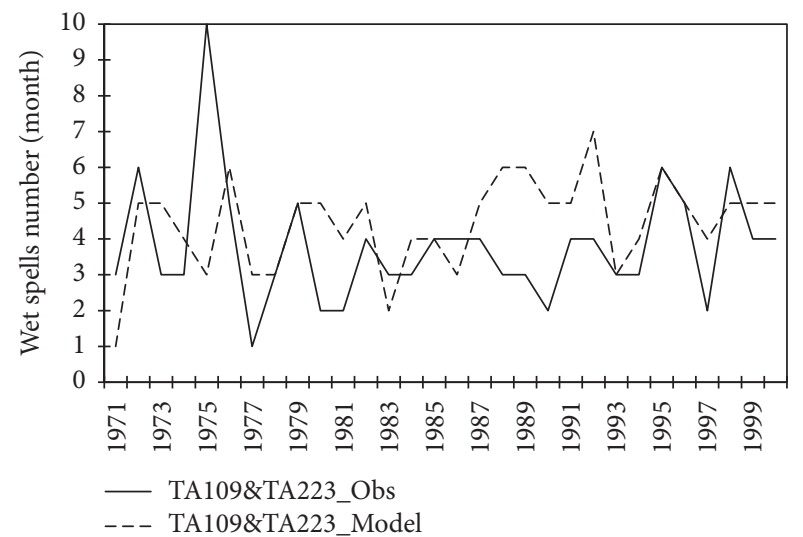

(b) TA109\&TA223

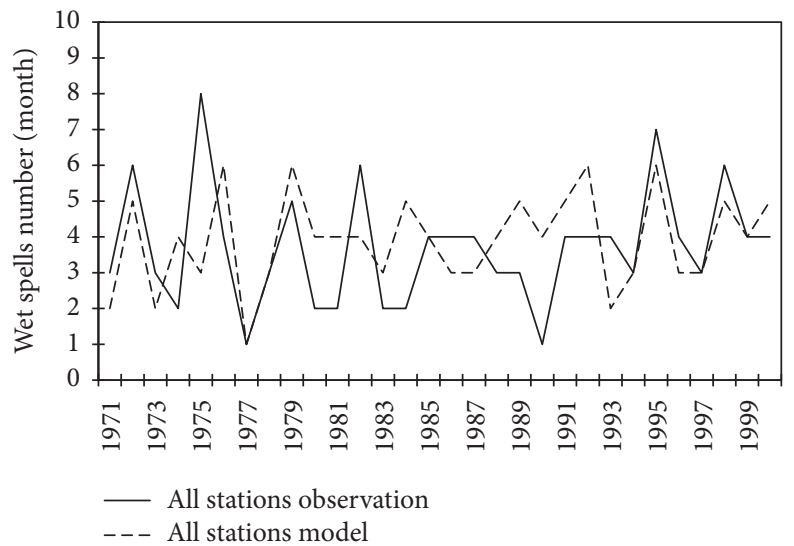

(c) All 4 stations mean

FIGURE 6: Number of wet spells obtained from observations and RegCM4 driven with HadGEM2 model monthly precipitation for (a) J107 and J108, (b) TA109 and TA223, and (c) all 4 stations mean for the base period 1971-2000.

(3) In order to prove that there is climate change impact on the duration of wet spell in the study area, the probability distribution functions (PDFs) of average scenarios for four stations are presented in Figure 7 along with the observations and average of RegCM4 driven with HadGEM2 data for the base period. Keep in mind that PDFs for the future period are only comparable with model data for the base period and not with observations. The observed PDF is only used for comparison with the model base period curve. In Figure 7, the RCP8.5 scenario shows a slight increase in the wet spell duration during the periods 2020-2049 and 2070-2099.

Figure 7 shows PDF plots of model and observation data against the duration of wet spells on a monthly basis. For the base period, the model PDF plot is to the right of the observation data, which indicates overestimation of the duration of wet spells by the model data. During this base period both the model and observations curves are showing a bit difference in terms of position and magnitude. The PDF curves over the entire projection period (i.e., RCP4.5 2020-2049, RCP8.5 2020-2049, and RCP8.5 2070-2099) lie to the right of the model plot for the base period, indicating an increase in the

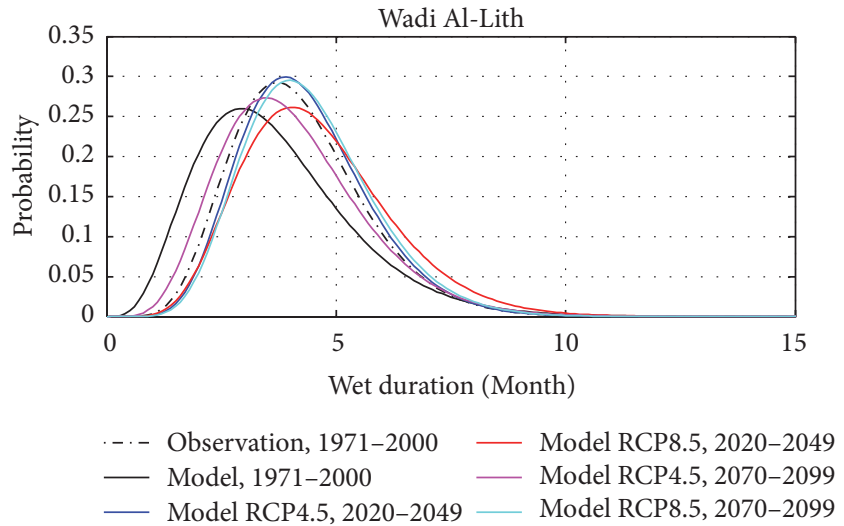

FIGURE 7: Duration of wet spells model risk probability distribution functions (PDFs) for the base, near future, and far future periods. RCP4.5 and RCP8.5 data are used for RegCM4 driven with HadGEM2 projections.

duration of wet spells, hence implying that climate change has an impact on the study area. The increase in the duration of wet spells is expected to replenish groundwater stores in the future and also to enhance agricultural activities. On 


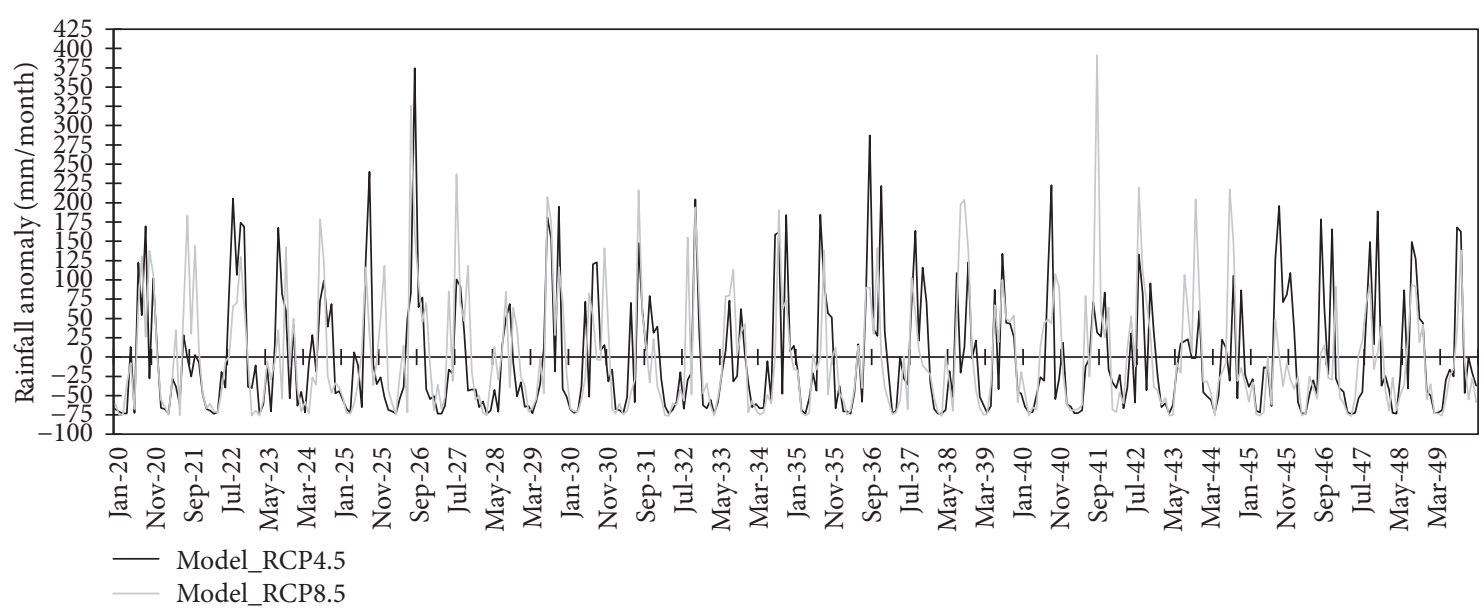

(a) Wet and dry spells, 2020-2049

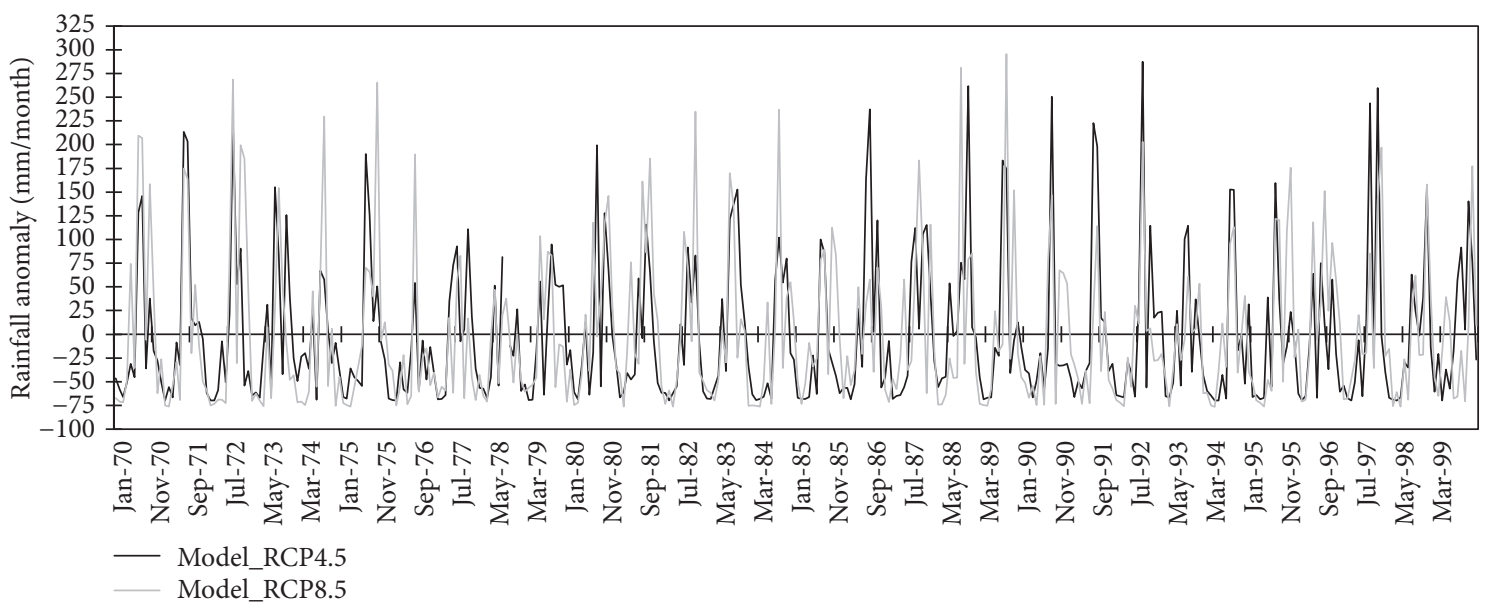

(b) Wet and dry spells, 2070-2099

FIGURE 8: Monthly precipitation anomalies obtained from RegCM4 driven with HadGEM2 data for the periods 2020-2049 (a) and 2070-2099 (b) for RCP4.5 and RCP8.5. Zero is the average value over the two periods which have values equivalent to $73.71(69.25)$ and $76.37(76.45) \mathrm{mm}$ for RCP4.5 and RCP8.5, respectively, in 2020-2049 (2070-2099).

the basis of Figure 7 and following relevant analysis of PDFs of wet (dry) monthly precipitation the following points are highlighted.

(i) All $f(x)$ mentioned in (3)-(10) are tested one by one to find the best fit, which is Gamma (see (8)) in this analysis.

(ii) Duration of monthly wet (dry) spells fits Gamma PDFs closely for the observed and predicted monthly precipitation amounts.

(iii) Monthly precipitation projections are expected to show comparatively longer wet spells in the future, implying an indirect increment in precipitation amounts.

(iv) The Gamma PDF parameters are different from each other, but they are all in accordance with the same PDF.

The wet and dry spells obtained from precipitation anomalies over the 30-year periods for the near and far future using RCP4.5 and RCP8.5 scenarios indicate that there is not much difference between the two scenarios (Figure 8). Both scenarios provide more or less the same number of spells, except that the magnitudes are not the same for some spells. The peaks in the two scenarios shift by about $8 \%$ and 7\% for the periods 2020-2049 and 2070-2099, respectively. Hence, the uncertainty of precipitation peak identification between the two RCP scenarios is within $10 \%$. The surplus and deficit amounts are used to calculate the characteristics of wet and dry spells during the projection period and the changes relative to the base period are presented.

Figure 9 shows the annual cumulative number of wet spells for the projection period 2020-2099 for the average of downstream stations, upstream stations, and four stations based on the RCP8.5 scenario, while in the interests of brevity the comparable figures are not shown for RCP4.5 because they are identical to RCP8.5 (see Figure 9). There is an interannual variation in the number of wet spells; that is, the number of wet spells varies from year to year. 


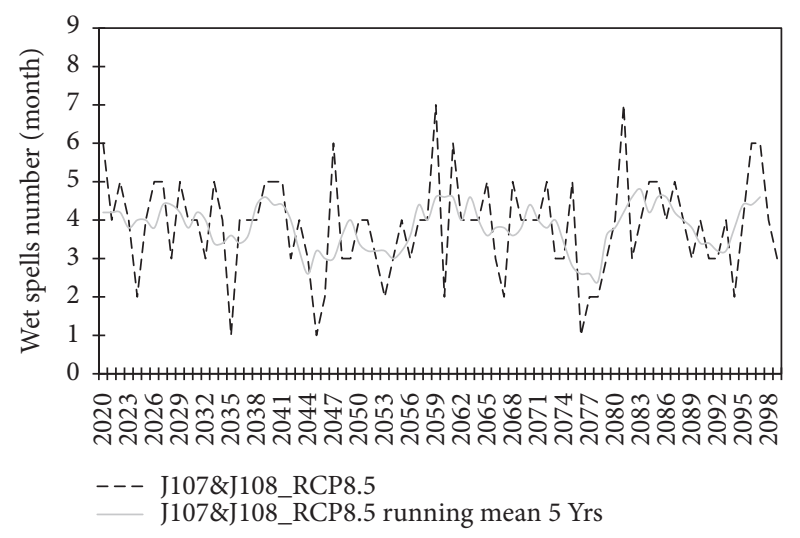

(a) $\mathrm{J} 107 \& \mathrm{~J} 108$

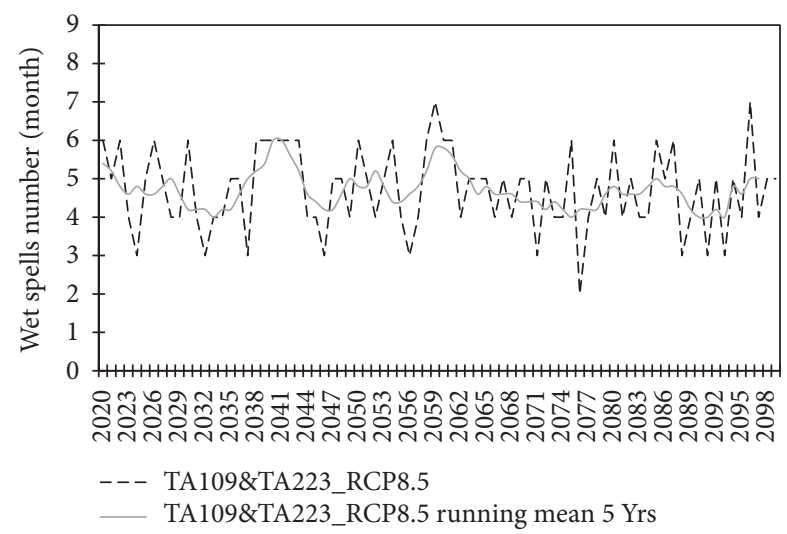

(b) TA109\&TA223

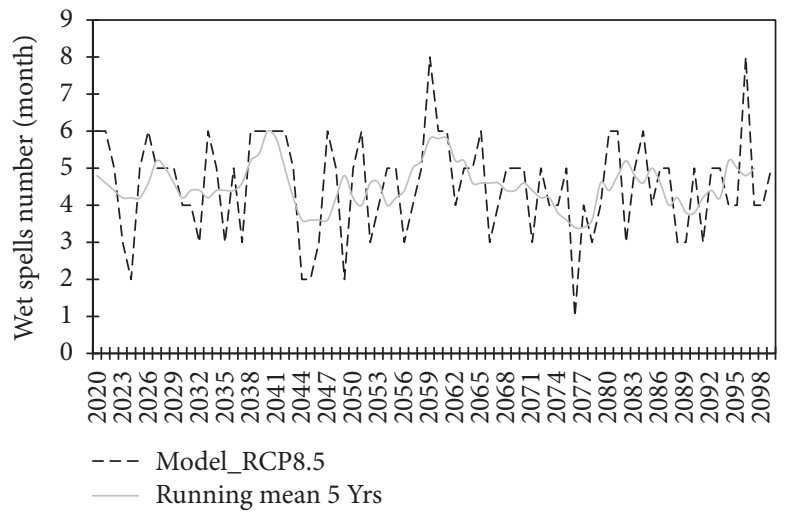

(c) All 4 stations

FIGURE 9: Number of wet spells (in month) obtained from RegCM4 driven with HadGEM2 monthly precipitation for (a) J107 and J108, (b) TA109 and TA223, and (c) all 4 stations mean for the period 2020-2099. The gray line represents the 5-year running mean.

Although the variation is almost constant for the overall period (2020-2099), for all stations average it is positive and higher for the far future ( 0.33 per decade) compared to the near future $(-0.28$ per decade).

For the upstream (downstream) stations average the number of wet spells variations is $1.38(0.22)$ for the far future compared to the $-0.05(-0.42)$ in the near future. The standard deviations $1.07,1.27$, and 1.34 for, respectively, upstream stations, downstream stations, and all stations average indicated that the number of wet spells varies within a small range. The 5-year running mean indicates an interval peak of almost 20 years for wet spell for upstream and all stations average over the total projection period. This interval peak is a bit random for the downstream stations average.

The change in the number of wet spells over the projection period compared to the base period under the RCP8.5 is shown in Figure 10. The result looks similar to that shown in Figure 9, although the standard deviation is slightly increased for all stations average (1.42).

Moreover, amount of the three GCMs (HadGEM2, GFDL, and ECHAM6) average precipitation at different risk levels is projected to increase more in the far future than in the near future compared to the historical base period (Figure 11). Hence, the slight increase in the number of wet spells and the increase in the amount of precipitation in the far future compared to the near future are a valuable piece of information for water resource management and agricultural plans for the study region. In case of downstream stations average, for the base period, the model is overestimated for all risk levels but underestimated for risk levels 1 and 2 (Figure 11(a)). For the upstream stations average, the model is overestimated for all risk levels but measures similarly for level 1 (Figure 11(b)). Results show that, for the base period (1971-2000) for all stations average, the model overestimates precipitation by about $37,50,66,97,127$, and $270 \%$ for the risk level 1, 2, 4, 10, 20, and 50\%, respectively (Figure 11(c)). This indicates large uncertainty in the model-estimated precipitation, which, as mentioned earlier, was not free from limitation until now. Therefore, the use of more GCMs including newly developed Saudi-KAU model [40, 41] to drive RegCM4 might be helpful to prepare a multimodel ensemble for applicationoriented tasks including rainfall harvesting in the context of climate change in the region. This paper provides a base document on the utility of climate model data.

\section{Conclusions}

Duration of wet spells is crucial for agriculture, water resource systems, and certain management sectors especially in arid regions. In practical applications, knowledge on the 


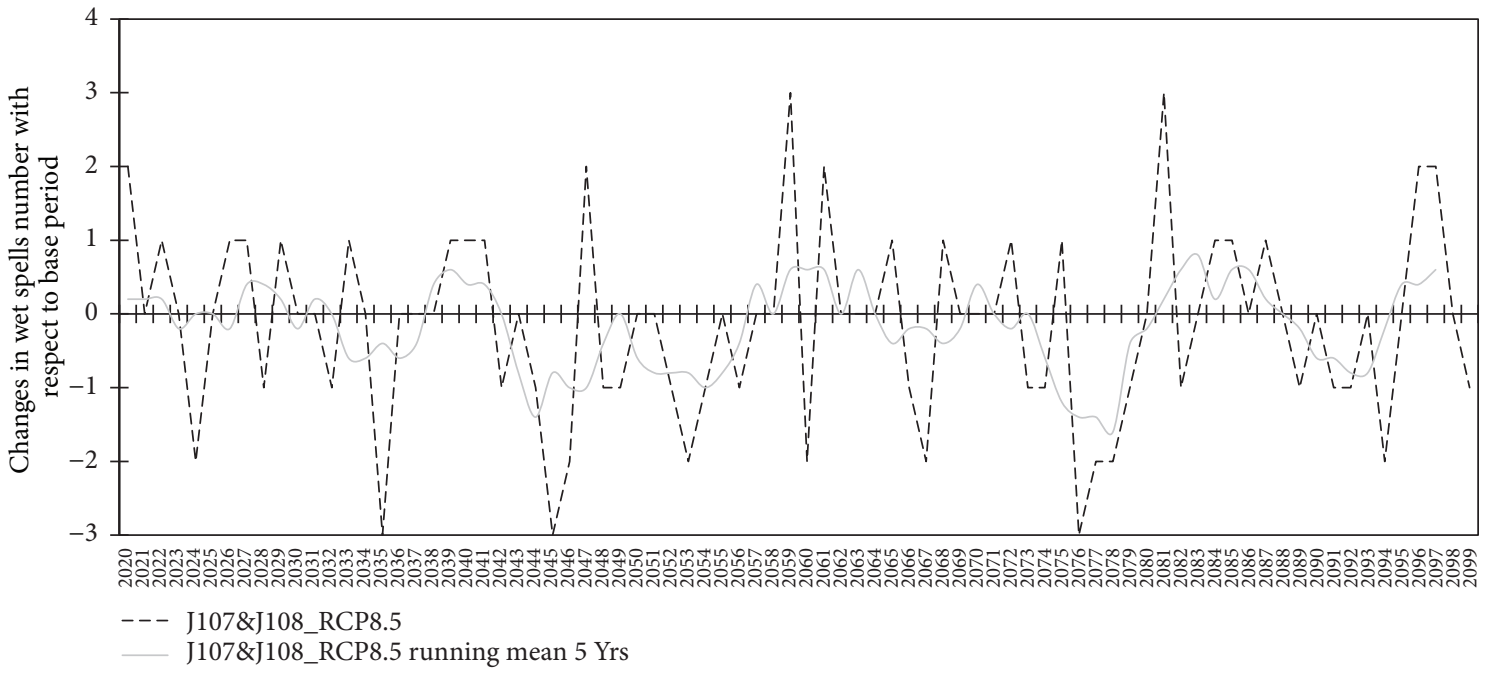

(a) $\mathrm{J} 107 \& \mathrm{~J} 108$

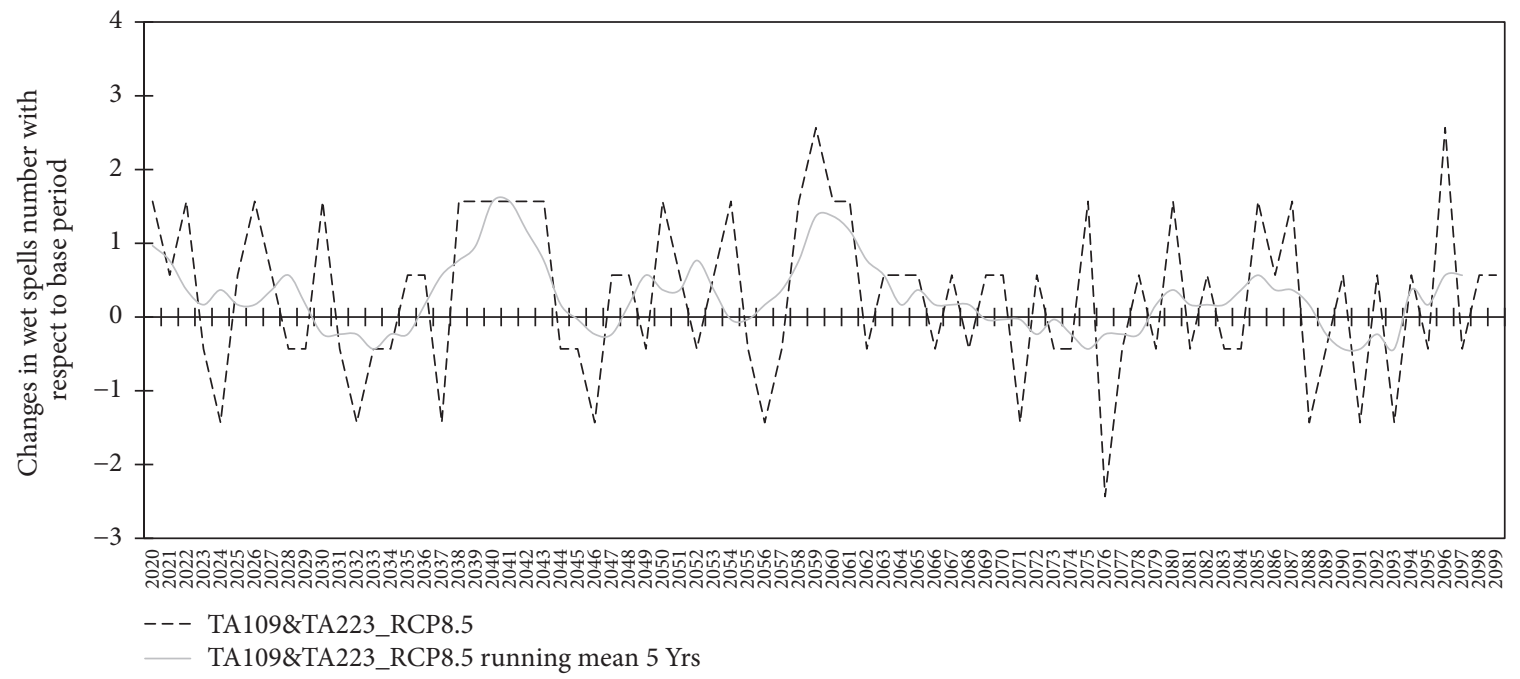

(b) TA109\&TA223

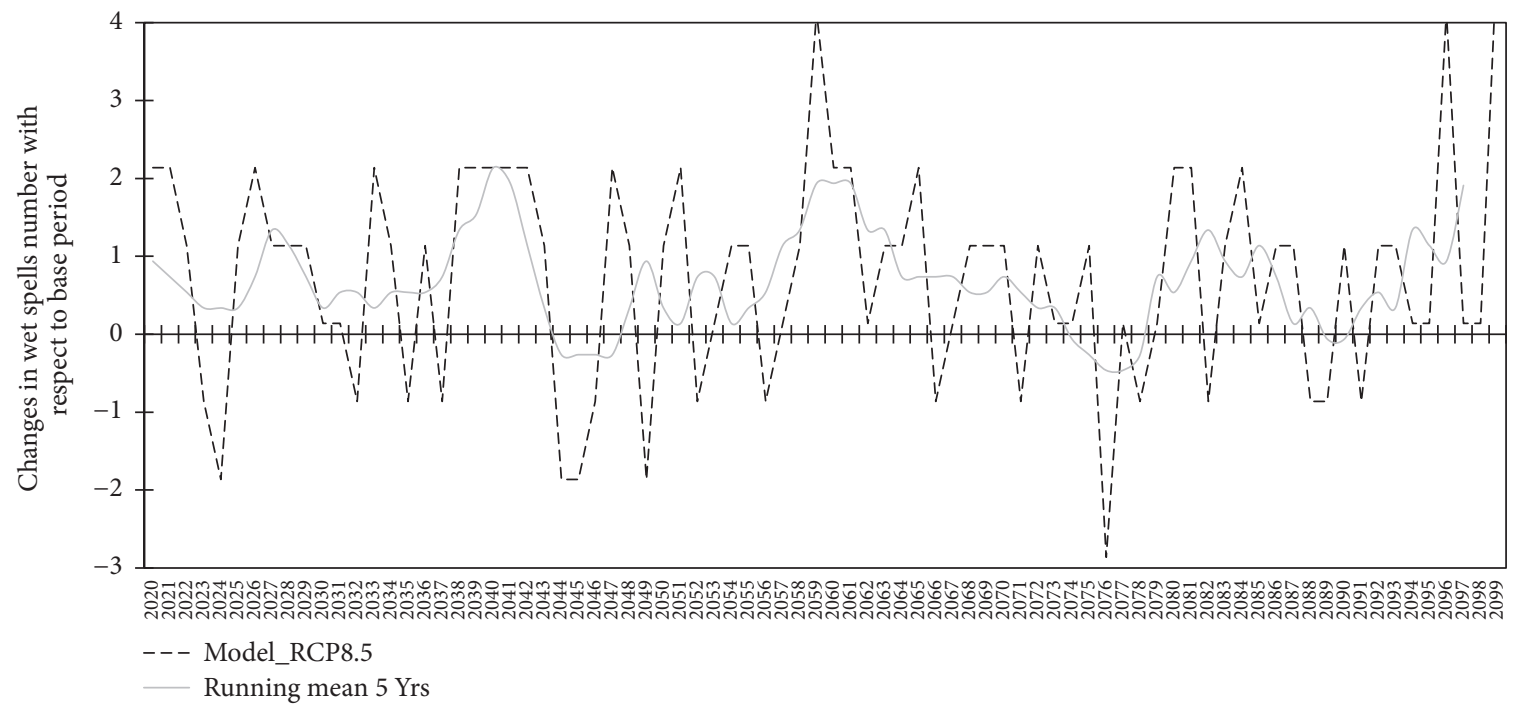

(c) All 4 stations

FIGURE 10: Change in the number of wet spells obtained from model monthly precipitation for (a) J107 and J108, (b) TA109 and TA223, and (c) all 4 stations mean for the period 2020-2099 relative to the base period (1971-2000). The gray line represents the 5-year running mean. 


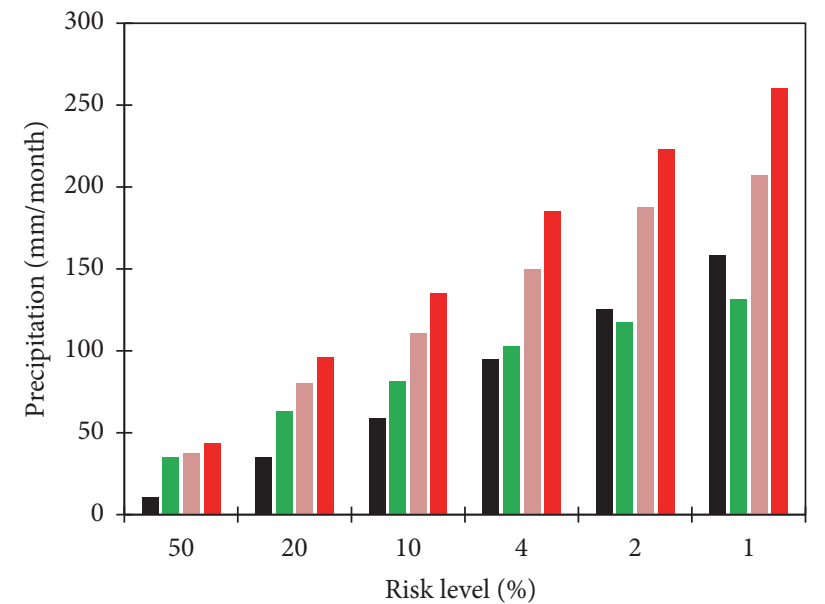

• J107J108_Obs 1971-2000 [ J107J108_Model 1971-2000
- J107J108_RCP8.5 2020-2049

• J107J108_RCP8.5 2070-2099

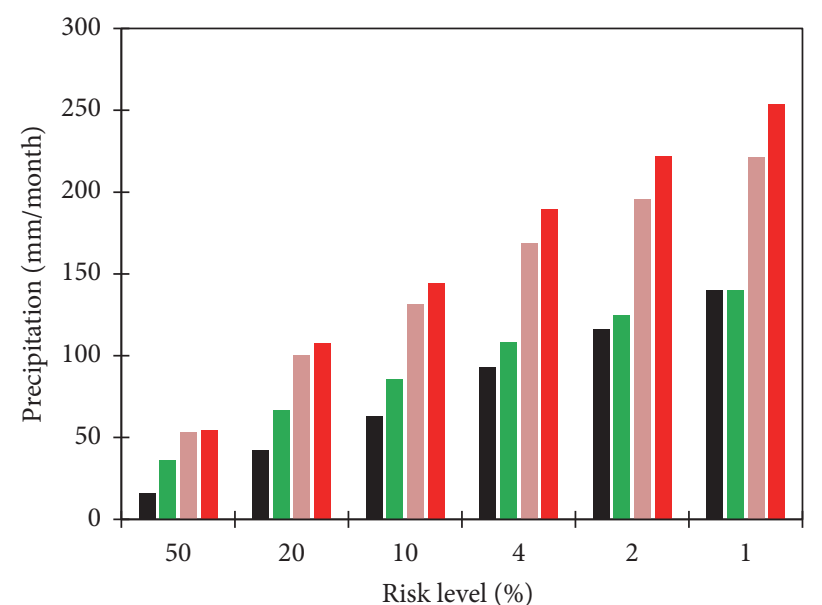

- TA109TA223_Obs 1971-2000 - TA109TA223_RCP8.5 2020-2049 — TA109TA223_Model 1971-2000 TA109TA223_RCP8.5 2070-2099

(b) TA109\&TA223

(a) $\mathrm{J} 107 \& \mathrm{~J} 108$

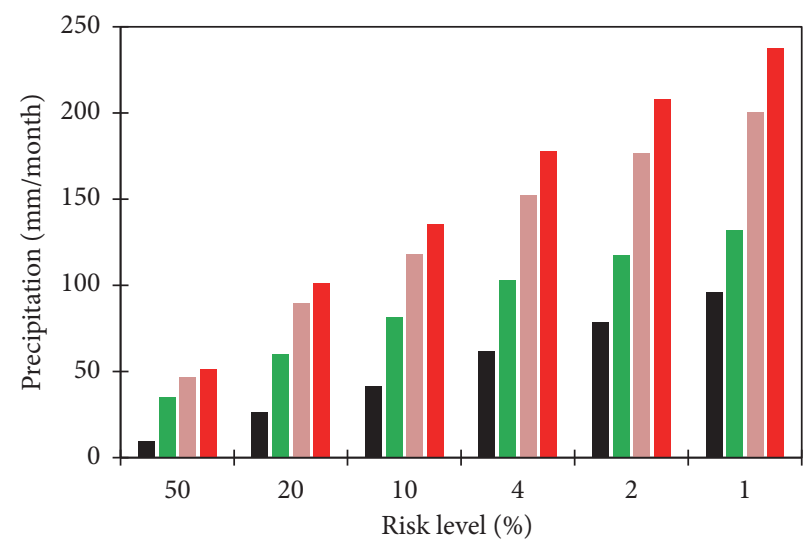

- All_Obs 1971-2000 - All_Model 1971-2000

- All_RCP8.5 2020-2049

• All_RCP8.5 2070-2099

(c) All 4 stations

FIGURE 11: The amount of precipitation ( $\mathrm{mm} / \mathrm{month}$ ) at different risk levels (\%) for the observation and 3 GCMs average base period and RCP8.5 for near and RCP8.5 for future periods in case of (a) J107 and J108, (b) TA109 and TA223, and (c) all 4 stations. Model data are averaged from three GCMs (HadGEM2, GFDL, and ECHAM6).

duration of monthly wet (dry) spells is vital for decision making. In this paper, the duration of wet spells is analyzed against average observations from four meteorological stations and regional climate model projections based on RCP4.5 and RCP8.5 scenarios using HadGEM2, GFDL, and ECHAM6 as boundary forcing to drive RegCM4. The analysis was carried out successfully on Wadi Al-Lith in the western province of Saudi Arabia. Monthly precipitation records at the two downstream stations, two upstream stations, and all four meteorology stations were averaged and compared with the climate model results for the base period 1971-2000. It was observed that while the climate model successfully captured the pattern of wet and dry spells during the base period, it overestimated number of wet spells within $\pm 5 \%$ relative error for all stations average, hence giving confidence in the model's ability to capture spell duration historically. On the other hand, the analysis of climate change simulations, average over all stations, reveals that the number of wet spells is likely to be stable (standard deviation 1.34) for the period 2020-2099, although there is a slight increase (standard deviation 1.42) in the number of wet spells, that is, decrease of the number of dry spells towards the end of the 21st century compared to the near future (2020-2049). Moreover, the model scenarios show higher values for the number of wet spells in the future compared to the base period and vice versa for the number of dry spells. In addition, an increase in the duration of wet spells was observed in the future compared to the base period. This finding is a valuable piece of information for planning of water system design and for management and agricultural sectors in the study area though large uncertainty is present in the model precipitation results. In future, a similar analysis using an ensemble from many GCMs may prove useful for the assessment of uncertainties involved in the projections, hence providing more accurate results for decision makers. 


\section{Conflicts of Interest}

The authors declare that they have no conflicts of interest.

\section{Acknowledgments}

This project was funded by the National Plan for Science, Technology and Innovation (MAARIFAH), King Abdulaziz City for Science and Technology, the Kingdom of Saudi Arabia, Award no. 11-WAT1999-03. The authors also acknowledge with thanks Science and Technology Unit, King Abdulaziz University, for technical support. The ICTP, Trieste, Italy, is acknowledged for providing RegCM and driving data. Computation for the work described in this paper was performed using Aziz Supercomputer at King Abdulaziz University's High Performance Computing Center, Jeddah, Saudi Arabia.

\section{References}

[1] Z. Şen, Applied Drought Modeling, Prediction, and Mitigation, Elsevier, 2015.

[2] M. Choi, J. M. Jacobs, M. C. Anderson, and D. D. Bosch, "Evaluation of drought indices via remotely sensed data with hydrological variables," Journal of Hydrology, vol. 476, pp. 265273, 2013.

[3] A. K. Mishra and V. P. Singh, "A review of drought concepts," Journal of Hydrology, vol. 391, no. 1-2, pp. 202-216, 2010.

[4] M. Almazroui, M. N. Islam, K. S. Balkhair, Z. Şen, and A. Masood, "Rainwater harvesting possibility under climate change: A basin-scale case study over western province of Saudi Arabia," Atmospheric Research, vol. 189, pp. 11-23, 2017.

[5] K. L. Whitworth, D. S. Baldwin, and J. L. Kerr, "Drought, floods and water quality: Drivers of a severe hypoxic blackwater event in a major river system (the southern Murray-Darling Basin, Australia)," Journal of Hydrology, vol. 450-451, pp. 190-198, 2012.

[6] Z. şen, "Critical drought analysis by second-order Markov chain,” Journal of Hydrology, vol. 120, no. 1-4, pp. 183-202, 1990.

[7] Z. Şen, "Probabilistic formulation of spatio-temporal drought pattern," Theoretical and Applied Climatology, vol. 61, no. 3-4, pp. 197-206, 1998.

[8] Z. Şen, "Spatially heterogeneous drought analysis theory and future trends," Journal of Hydrology, vol. 519, pp. 1804-1810, 2014.

[9] H. Hisdal and L. M. Tallaksen, "Estimation of regional meteorological and hydrological drought characteristics: a case study for Denmark," Journal of Hydrology, vol. 281, no. 3, pp. 230-247, 2003.

[10] A. G. Dai, "Drought under global warming: a review," Wiley Interdisciplinary Reviews: Climate Change, vol. 2, no. 1, pp. 4565, 2011.

[11] S. Madadgar and H. Moradkhani, "Drought analysis under climate change using copula," Journal of Hydrologic Engineering, vol. 18, no. 7, pp. 746-759, 2013.

[12] K. Xu, D. Yang, H. Yang, Z. Li, Y. Qin, and Y. Shen, "Spatiotemporal variation of drought in China during 1961-2012: a climatic perspective," Journal of Hydrology, vol. 526, pp. 253264, 2015.

[13] G. E. P. Box and G. M. Jenkins, Time Series Analysis: Forecasting and Control, Holden-Day, San Francisco, Calif, USA, 1976.
[14] J. R. Green, "A model for rainfall occurrence," Journal of the Royal Statistical Society. Series B. Methodological, vol. 26, pp. 345-353, 1964.

[15] E. H. Wiser, "MOdified markov probability models of sequences of precipitation events," Monthly Weather Review, vol. 93, no. 8, pp. 511-516, 1965.

[16] A. M. Feyerherm and L. D. Bark, "Goodness of Fit of a Markov Chain Model for Sequences of Wet and Dry Days," Journal of Applied Meteorology, vol. 6, no. 5, pp. 770-773, 1967.

[17] S. C. Kao and R. S. Govindaraju, "A copula-based joint deficit index for droughts," Journal of Hydrology, vol. 380, no. 1-2, pp. 121-134, 2010.

[18] G. A. Theoharatos and I. G. Tselepidaki, "The temperature of the sea-surface in the region of the Aegean and its relation to air temperature," Theoretical and Applied Climatology, vol. 42, no. 2, pp. 117-119, 1990.

[19] G. A. Theoharatos and I. G. Tselepidaki, "The distribution of rainy days in the Aegean area," Theoretical and Applied Climatology, vol. 42, no. 2, pp. 111-116, 1990.

[20] S. Blenkinsop and H. J. Fowler, "Changes in drought frequency, severity and duration for the British Isles projected by the PRUDENCE regional climate models," Journal of Hydrology, vol. 342, no. 1-2, pp. 50-71, 2007.

[21] M. Guardiola-Claramonte, P. A. Troch, D. D. Breshears et al., "Decreased streamflow in semi-arid basins following droughtinduced tree die-off: A counter-intuitive and indirect climate impact on hydrology," Journal of Hydrology, vol. 406, no. 3-4, pp. 225-233, 2011.

[22] B. C. Bates, Z. W. Kundzewicz, S. Wu, and J. P. Palutikof, Climate Change and Water VI, Intergovernmental Panel on Climate Change, Geneva, Switzerland, 2008.

[23] S. M. Vicente-Serrano, "Spatial and temporal analysis of droughts in the Iberian Peninsula (1910-2000)," Hydrological Sciences Journal, vol. 51, no. 1, pp. 83-97, 2006.

[24] D. Gampe, R. Ludwig, K. Qahman, and S. Afifi, "Applying the Triangle Method for the parameterization of irrigated areas as input for spatially distributed hydrological modeling - Assessing future drought risk in the Gaza Strip (Palestine)," Science of the Total Environment, vol. 543, pp. 877-888, 2016.

[25] P. Dahal, N. S. Shrestha, M. L. Shrestha et al., "Drought risk assessment in central Nepal: temporal and spatial analysis," Natural Hazards, vol. 80, no. 3, pp. 1913-1932, 2016.

[26] J. Almedeij, "Long-term periodic drought modeling," Stochastic Environmental Research and Risk Assessment, vol. 30, no. 3, pp. 901-910, 2016.

[27] A. K. Mishra, V. P. Singh, and V. R. Desai, "Drought characterization: a probabilistic approach," Stochastic Environmental Research and Risk Assessment (SERRA), vol. 23, no. 1, pp. 41-55, 2009.

[28] A. Cancelliere and J. D. Salas, "Drought probabilities and return period for annual streamflows series," Journal of Hydrology, vol. 391, no. 1-2, pp. 77-89, 2010.

[29] G. Tsakiris, D. Pangalou, and H. Vangelis, "Regional drought assessment based on the reconnaissance drought index (RDI)," Water Resources Management, vol. 21, no. 5, pp. 821-833, 2007.

[30] F. Giorgi, E. Coppola, F. Solmon et al., "RegCM4: Model description and preliminary tests over multiple CORDEX domains," Climate Research, vol. 52, no. 1, pp. 7-29, 2012.

[31] M. Almazroui, "RegCM4 in climate simulation over CORDEXMENA/Arab domain: Selection of suitable domain, convection and land-surface schemes," International Journal of Climatology, vol. 36, no. 1, pp. 236-251, 2016. 
[32] M. Almazroui, M. N. Islam, A. K. Al-Khalaf, and F. Saeed, "Best convective parameterization scheme within RegCM4 to downscale CMIP5 multi-model data for the CORDEXMENA/Arab domain," Theoretical and Applied Climatology, vol. 124, no. 3-4, pp. 807-823, 2016.

[33] M. Almazroui, M. N. Islam, A. K. Alkhalaf, F. Saeed, R. Dambul, and M. A. Rahman, "Simulation of temperature and precipitation climatology for the CORDEX-MENA/Arab domain using RegCM4," Arabian Journal of Geosciences, vol. 9, no. 1, article no. 13, pp. 1-14, 2016.

[34] G. N. Summer, Precipitation Process and Analysis, John Wiley and Sons Co, New York, NY, USA, 1988.

[35] M. N. Islam and H. Uyeda, "Vertical variations of rain intensity in different rainy periods in and around Bangladesh derived from TRMM observations," International Journal of Climatology, vol. 28, no. 2, pp. 273-279, 2008.

[36] M. N. Islam, M. Rafiuddin, A. U. Ahmed, and R. K. Kolli, "Calibration of PRECIS in employing future scenarios in Bangladesh," International Journal of Climatology, vol. 28, no. 5, pp. 617-628, 2008.

[37] E. J. Gumbel, Statistics of Extremes, Columbia University Press, New York, NY, USA, 1958.

[38] G. W. Kite, Frequency and Risk Analysis in Hydrology, Water Res Publications, Fort Collins CO, 1977.

[39] K. Pearson, Tables of statisticians and biometricians, Part I. The Biometric Laboratory, Cambridge University Press, London, UK, 3rd edition, 1914.

[40] M. A. Ehsan, M. Almazroui, and A. Yousef, "Impact of different cumulus parameterization schemes in SAUDI-KAU AGCM," Earth Systems and Environment, vol. 1, no. 1, 2017.

[41] M. Almazroui, O. Tayeb, A. S. Mashat et al., "Saudi-KAU coupled global climate model: description and performance," Earth Systems and Environment, vol. 1, no. 1, 2017. 

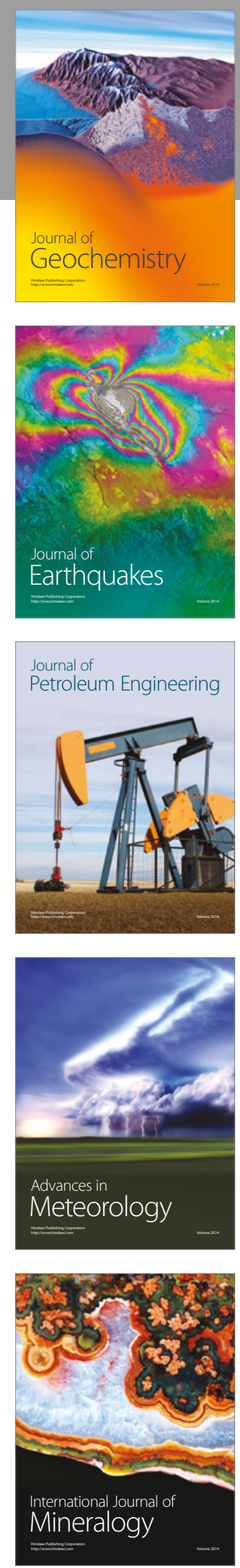
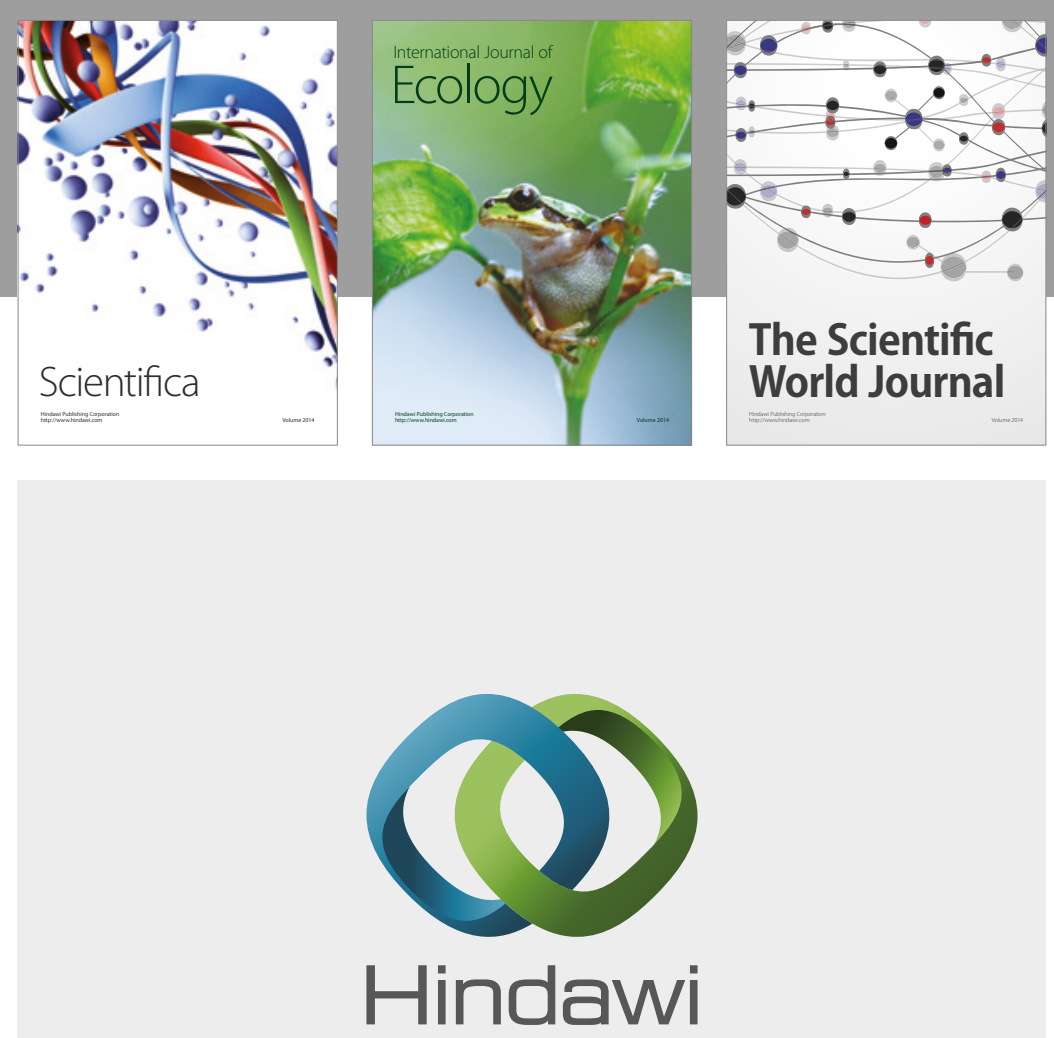

Submit your manuscripts at

https://www.hindawi.com
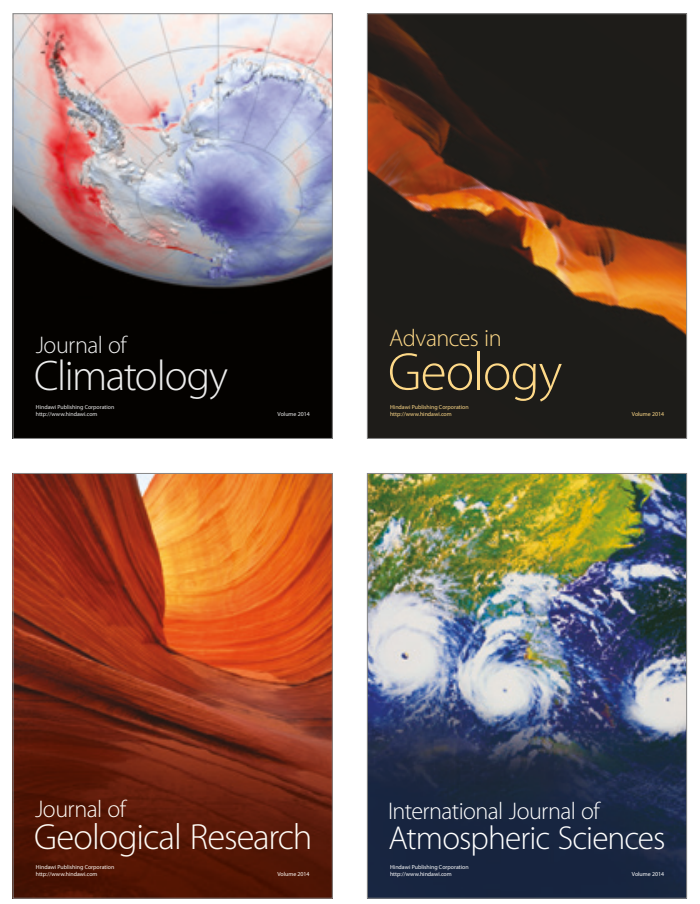

The Scientific

World Journal
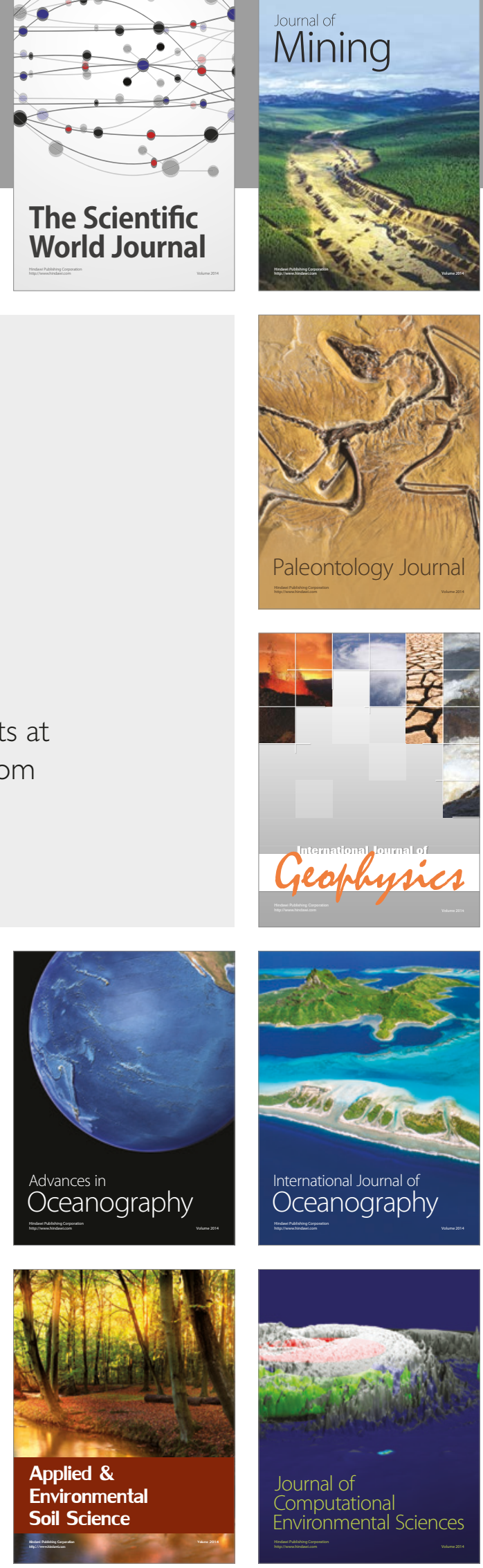